\title{
A life cycle model of major innovations in operations management
}

\author{
Attila Chikán ${ }^{{ }^{*}}$ (I) and Linda G. Sprague ${ }^{2^{\wedge}}$
}

\author{
* Correspondence: \\ attilachikan@gmail.com \\ Linda G. Sprague is deceased. This \\ paper is dedicated to his memory. \\ ${ }^{1}$ Institute of Business Economics, \\ Corvinus University of Budapest, \\ Budapest, Hungary \\ Full list of author information is \\ available at the end of the article
}

\begin{abstract}
This paper analyses the means by which major innovations in the operations management (OM) practice develop. It describes the process as having a life cycle pattern that starts with a big idea. The big idea concept promises breakthrough operating results, ultimately providing lower price, better quality, faster delivery, or combinations of these and other attributes that add value for the customer. A successful big idea goes through the phases of provenance, experimentation, penetration, consolidation, and absorption. At that point, it is being incorporated into business operations throughout the industry. If the original idea reaches the end of its useful life or proves unsuccessful during development, it is supplanted. Materials requirements planning (MRP) and supply chain management (SCM) are used to illustrate the general life cycle model. The analysis of these two successful major OM innovations discloses a similar development pattern but different final absorption outcomes. While MRP became an everyday tool for tactical level operations, SCM is an important strategic tool for integrated company management. The similarity of their development patterns, however, supports the general nature of the life cycle model introduced.
\end{abstract}

Keywords: OM development, Life cycle model, MRP, SCM, Integrated management

\section{Introduction}

One of the characteristic features of business is permanent change. There are no two days in the life of a company that would be identical. Some of the changes are minor and reversible; others are major, having a long lasting effect on company operations. Some changes may be unexpected consequences of random events while some are intended, perhaps even planned, for a long period of time. Through these changes, there is a more or less common objective, however, toward which managers direct their operations. They are developing ways of meeting customer requirements more effectively, with higher productivity, lower cost, or other performance measures appropriate to the times and business environments.

In this paper, we analyze some aspects of the seemingly chaotic process of developing a major innovation in operations management using a conceptual model of the life cycle of new business ideas. Of course, every case is different; however, we find that there are some common features that frequently appear with more or less the same characteristics in the origination and fate of new ideas. In this paper, we first analyze the development process in general, gradually building up and discussing the

(c) The Author(s). 2019 Open Access This article is distributed under the terms of the Creative Commons Attribution 4.0 International License (http://creativecommons.org/licenses/by/4.0/), which permits unrestricted use, distribution, and reproduction in any medium, provided you give appropriate credit to the original author(s) and the source, provide a link to the Creative Commons license, and indicate if changes were made. 
conceptual model and then we use two important cases to illustrate the model: (1) the emergence, spread, and gradual expansion of the materials requirements planning (MRP) concept and (2) the change from a purely technical distribution function to supply chain management (SCM) systems, one of the key strategic approaches to contemporary integrated company management. Both MRP and SCM have a fundamental influence on how operations are managed in business today. The history of the two is rather different but both illustrate the validity of our conceptual model.

"The big idea concept" section presents the "big idea" concept (an innovative idea that promises to fundamentally change the operations and performance of an organization). The reasons and sources of emerging a big idea and the conditions of its successful implementation are discussed. "The life cycle approach to developing OM practice innovation" section describes the life cycle approach to the development process of OM innovations which eventually leads to either absorption or rejection of the original idea. In the "Two examples to illustrate the development process" section, the history of two major innovation processes, the introduction of the MRP and the SCM concepts into practice, are analyzed. The "Conclusions" section summarizes the conclusions, comparing similarities and differences of the two life cycles and their actual impact on OM practice.

\section{The big idea concept}

The trigger for the development of a major innovation in managing operations is an idea: a big idea. In this paper, our interest is on ideas that, at the time of their emergence, seem to bear the promise of breakthrough results. Big ideas can have fundamental effects on a company's operations and performance, thus attracting other firms in the industry to use the idea. Such big ideas can appear in a variety of forms: as a method of doing things, a technique for planning, using a new technology for solving problems, a system of connecting activities, or a philosophy offering new approaches. It is a common characteristic of these big ideas that even experts believe that they can revolutionize some aspects or areas of business activity. They promise to lead to performance improvement but they may not have yet gone through a conscious, planned development process.

We believe that big ideas can be very important factors of business development. Since they promise important positive outcomes, it is important to analyze the process by which they are developed. Big ideas can affect an entire industry, so we focus our attention on big ideas. Also, there is a body of literature that describes the big idea in the general development process. (For a discussion of these processes, see Letscher [1], Spell [2], and Williams [3]).

Since we are interested in the way that big ideas develop, we consider why and how they emerge. Here are some reasons that have been suggested:

- The most important reason is probably the pressure that originates from the constant changes in business mentioned in the introduction. There is an urge to respond to those changes proactively and grab the ideas that seem to help handling both the internal pressure (arising usually in the form of performance gaps and dissatisfaction with processes and/or results) and the external pressure (stemming from some competitiveness gaps or change in the market). 
- Management wants to be seen as innovative. It is a natural expectation inside the company and socially conforming if they can meet this requirement that they should come up with new ideas. It is, at least in many cases, also the internal need of the managers who themselves seek new results. (Of course, not only managers can come up with the big ideas-other professionals of the company may also do so).

- Last, but not least, generating new ideas is part of the culture of competitive companies. They certainly know that they can stay competitive only if they do so. They learn from their own experience and by watching others that if they want to differentiate themselves they cannot just follow industry trends.

Big ideas comply with these conditions, as they promise great (sometimes disproportionately high) results and often require relatively little effort to generate. The big question, of course, is whether their acceptance and implementation can actually deliver the results or not. The proof of this usually does not occur immediately but is a result of the development process. For those who are able to implement the big idea, it becomes a source of innovation and competitive advantage. But early discovery of unsuccessful big ideas is important to save development costs and time for working on other big ideas.

It is not easy to advance from a big idea to a successful innovation. Letscher [1] lists a number of conditions that must be met to achieve this. These conditions may be summarized as follows:

- To prove successful the big idea must fit the basic culture of the company and, more generally, the society where it is applied. (Think of the difficulties and differentiated results of spreading the Japanese management ideas and techniques throughout the world.)

- It must offer significant benefits and the payoff must be proven by objective assessment of the results.

- It must be supported and promoted by key users and influential leaders.

- It must get to the essence of the problem(s) it addresses, not just scratch the surface. For this to occur it must be adaptable to the specific needs of the companies applying the idea.

Of course, during the development of a new big idea, a company can tell whether these conditions are met or not. Most major innovations stem from big ideas that address fundamental, systemic components of operations management while other ideas touch some specific (though perhaps important) limited activity. One should not neglect these other ideas. For example, the Japanese car industry benefitted vastly from the idea of "continuous improvement," which means the serial application of many "small" ideas. The spread of any successful idea, big or small, is not limited to in-company processes, but may spread throughout the industry, as did the continual improvement idea.

We acknowledge the importance of "small" ideas, but still concentrate in this paper on big ideas that demonstrate the possibility of management breakthroughs. The development process may not be substantially different between the small and big 
ideas. The adaptation by a company, the industry, and, ultimately, the OM profession may be quite different, however. The application of a special tool, changing a process in a specific way, or using some new material may lead to a better product or a less expensive process but rarely transforms the management of operations. For these reasons, we will analyze the development process in terms of big ideas and will illustrate the full life cycle with two very big ideas: MRP and SCM.

\section{The life cycle approach to developing OM practice innovation}

Businesses are among the most dynamic institutions in today's society. Under the pressure of fierce competition business, managers must quickly come up with new ideas in order to survive. This is the main reason why most innovations in management originate in business itself rather than follow research results. Innovations that change systems, modify processes, revolutionize business functions, have far-reaching impacts, and otherwise affect general management practices are usually based on a big idea. Thus the birth of a big idea is the first phase of the development life cycle.

\section{The birth of a big idea}

As shown in Fig. 1, the birth of a big idea initiates the life cycle of the development of an operations management practice innovation. The big idea itself is often an answer to some important question(s) arising from the changing requirements of business operations. (A similar approach is found in Voss [4]) Once the development process is initiated, it moves to the next phase: provenance.

\section{Provenance}

In the provenance phase, the big idea is put into practice and provides a competitive advantage (the first mover advantage) for the company that introduced it. In this phase, the idea has been shown to be successful; otherwise, the company would quickly

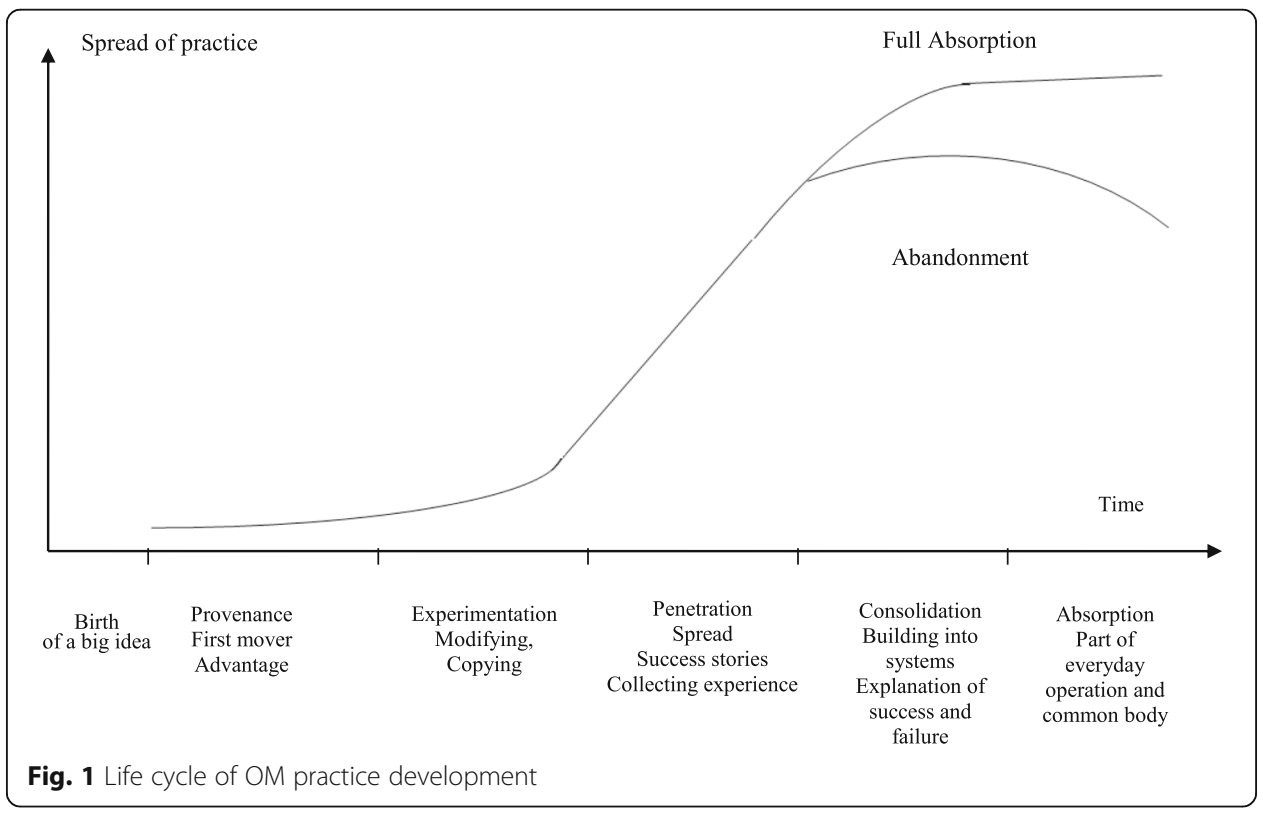


abandon it. Regardless of whether the company developed the new practice for its own internal or an external requirement, the competitive advantage is virtually impossible to keep secret. Business partners, customers, suppliers, or competitors, or maybe all of them, will learn of the new development.

In many cases, in order to make partnership improvements or to enhance their image for marketing purposes, the originator company itself tells the story about the development. The dissemination of information on the development continues during the provenance phase, so other firms listen and learn about the innovation, thus leading to the next phase of the life cycle, experimentation.

\section{Experimentation}

In the experimentation phase, other companies, often competitors in the same industry, start imitating, copying, and modifying the new practice. The success or failure of these new applications depends on the availability of details on the implementation, a correct understanding of the innovation, and the similarity of circumstances of application. Accordingly, this phase is characterized by the appearance of positive and negative feedback about the new approach. As word spreads, new companies and circumstances enter the scene and bring new resources to the experimentation.

As an example, consultants see business opportunities in understanding the innovation and applying it among their clients. They give advice on how to use or modify the new approach for their clients' businesses. In the process, the consultants are learning the real essence of the new approach. As knowledge is gained, the experimentation phase gradually slips into the next phase, which is penetration.

\section{Penetration}

During the penetration phase, dissemination of information about the innovation continues and sparks additional interest among companies and consultants. If consultants find the new approach adds value for their clients, they are ready to invest serious resources to uncover the actual conditions under which the new system, method, or approach can be successfully applied. They attend conferences, seminars, and other professional events giving accounts of their results and relating their success stories.

In many cases professional associations, whose mission usually includes the dissemination of new knowledge, support these conferences. If the feedback is mostly positive, they start to include this knowledge in their professional development programs' syllabi, seminars, and courses. The professional association sponsorship activities provide credibility for the new approach which can lead to a positive spiral in implementations. As penetration increases, the application of the new approach is less a source of competitive advantage, but more a competitive necessity. If the new approach is not yet fully deployed through the industry, however, those that do apply it can still enjoy an advantage in the market.

Of course the new developments catch the attention of academics as well. As evidence of the innovations' popularity mounts, research projects are started to learn the answer to an important question that cannot be asked before there are some counter examples: Why are some companies successful at implementation while others fail? 
It is in the penetration phase that the embedment of the innovation into the body of knowledge starts. Answers to questions, like how is the new approach related to the "old" ones, what is really new in it, what consequences can be drawn from our new knowledge for future developments, are being incorporated. The turbulent processes of knowledge gaining and generalization lead to the next phase of the life cycle: consolidation.

\section{Consolidation}

The consolidation phase is the result of accumulation of knowledge, both practical and theoretical, that starts as early as the birth phase. This knowledge has made basically clear the essence of the innovation, under what circumstances it is successful, how it relates to previous practices, and how it is related to the other professional activities of the company. At some point, the conditions appropriate the market to expect all companies in the industry to use the new approach. Once the innovation becomes part of the common body of knowledge, it is the subject of academic textbooks and professional associations' development programs. Once there is deep penetration and widespread successful use, the approach continues smoothly and it becomes soil for the life cycle to start again and the next phase: absorption.

\section{Absorption}

Absorption is the last phase of the life cycle. If successful, the one-time big idea operates as part of everyday practice throughout the industry. It is discussed as part of the common body of knowledge in professional meetings, university classrooms, and in client engagements by consultants. Ultimately, another big idea will come along to supplant the current innovation, its useful life will be over, and the life cycle will come to an end even though some elements of the current practice may appear in future innovations.

But not all big ideas lead to absorption. Negative experiences in any of the earlier phases can lead to declaring the big idea unsuccessful. When a big idea does not succeed, researchers will still work on understanding the reasons for failure in order to provide insights that could be useful for the next big idea. It may turn out that any early success of the new approach was the result of some unique circumstances or had unexpected side effects later. It can happen that not all conditions for successful applications were revealed in previous phases or the new approach cannot be combined with other, perhaps better emerging big ideas. In these and other cases, the big idea fails and the life cycle finishes with decline and abandonment of the new approach.

\section{Two examples to illustrate the development process}

In this section, we describe two big ideas that are well known in operations management $(\mathrm{OM})$, material requirements planning and supply chain management. Both of them arose from a big idea and are now well absorbed into the body of OM knowledge. In the next pages, we describe them, using the life cycle model to illustrate their development. Both have had a major influence on how operations are managed today, especially in the production aspect of business where new value for the customer is physically created. We will also point out how big ideas in operations management evolve and that there is considerable continuity as new concepts are built on previous big ideas [5]. 


\section{Material requirements planning (MRP)}

The planning of materials requirements as an engineering/business activity is as old as industrial production itself. The materials and components to be used for creating a product always have to be determined and scheduled to arrive in advance of use in production. However, we had to wait until the late 1960s when the development of information technology made talking about material requirements planning (MRP) "systems" possible. These systems made possible an integrated management approach to solve the ancient problem.

There is a rich literature describing the development of MRP (see Mabert [6] for example). We use this literature and the life cycle model (Fig. 1) to trace the growth of MRP into a fully absorbed operations management practice. The big idea that launched the development was to use emerging computing power to do three things. The first was to calculate the total number of all the parts needed to complete the products to be produced. Secondly, manufacturing or purchasing times were then used to schedule the arrival or production of these parts in time for their use in production. Finally, the plans would be recalculated frequently to adjust the schedules to changing conditions.

The provenance phase was the early and mid-1960s when IBM promoted material planning software applications. They also joined with J.I. Case, a relatively small tractor manufacturer, to introduce an MRP like system for the company. The experimentation phase started in the late 1960s when George Plossl, Joseph Orlicky, and Oliver Wight, consultants with manufacturing management experience, began working with companies to implement MRP systems. As they worked with different companies in different industries, they gained knowledge about limitations, variations, and modifications that improved the generality of the concept and increased interest.

The penetration phase was boosted at the national convention of the influential American Production and Inventory Control Society (APICS) where the consultants were given program space. Moreover, the consultants convinced APICS to initiate an "MRP crusade," thereby spreading the idea throughout American manufacturing. As the MRP development moved into the consolidation phase, interest was growing among academics and textbooks began to appear [7, 8]. In 1974 and 1975, IBM sponsored a seminar for leading academics. These led to an improved understanding between academics and practitioners about the nature and significance of MRP. The amount of penetration and consolidation was underscored by the sale of several hundred thousand copies of a 1975 MRP article in the Harvard Business Review [9].

At this point with the absorption phase of MRP expanding, another big idea arose. It was sparked by the question "Can the MRP concept be extended to resources other than materials?" The provenance phase of this big idea was characterized by two factors in the economy. First was the rapid development of information technology that accelerated the availability of new computer capabilities. The second was the need for more integration of business processes to meet the Japanese productivity challenge. As experimentation with different resources (e.g., financial and human) and penetration into non-manufacturing industries occurred, there was a consolidation around the concept of MRP II. This was an integration of the planning of material and other (mainly financial) resources. Thus, we see the emergence of another big idea emerging from the MRP development life cycle. 
Academicians played a crucial role in the experimentation and penetration phases of the follow on of both the MRP and MRP II concept. Their research activity was very practice oriented, helping to understand and explain the operation of MRP and its extensions. Even though the theoretical background can be traced back to the 1950s [10], truly theoretical research came much later than related areas like inventory management or service systems (queuing systems). It is clear now that the strict mathematical analysis of MRP systems came only very recently, first of all by the works of Grubbström (The latest of a long list of papers is Grubbström [11], for newest developments and extensions see Bogataj-Grubbström [12, 13]).

Despite some arguments about the breadth of integration possible, consolidation around the concept of MRP II continued. This led to charges of "MRP imperialism" (i.e. that advocates were trying to include all operations management activities in MRP II) and others concerns about the highly appreciated just in time (JIT) systems, which could be connected to the success of Japanese manufacturers. (Indeed, at the First World Congress of APICS in Geneva, 1985 there was a session "MRP and JIT: friends or enemies?") Nevertheless, the experimentation with MRP II involved incorporating not only additional resources but also other manufacturing practices into MRP II.

Now MRP is part of practically all major management software packages as well as of all operations management textbooks. It is a natural part of company operations and is absorbed into the common body of management knowledge. The integration of additional resources and management practices into the MRP framework continues. We can follow the process of its development leading to MRP II and, ultimately, the development of Enterprise Resource Planning (ERP) (see Jacobs-Weston [14] and Samson-Singh [15]). The MRP development life cycle is presented in Fig. 2.

\section{Supply chain management (SCM)}

As with materials requirements planning, supply chain management has existed as a business function since the industrial revolution. The coordination of the flow of materials between suppliers and users, parts and assemblies between plants providing different aspects of production, and finished goods between producers and consumers has always been necessary. Independent organizational units (e.g., inventory management, transportation, warehousing, etc.) performed this task in the early part of the twentieth century. The big idea that launched the development of supply chain management (SCM) was that of integrating these independent units to achieve synergies [16].

Again, like MRP, it took some technical, competitive, and international changes to move SCM development to the provenance and experimentation phases. Among these changes were the advances in information technology in the mid-twentieth century that, in addition to increased computing power, enabled improved communication between units. The competitive pressures led to two big ideas in business strategy. One was the concept of core competencies; in which companies concentrate resources on those areas of activity in which they have competitive advantage. This led many companies to outsource non-core functions. Another was the increasing focus on customer satisfaction, which led to "marketing warfare," separating of marketing and sales, and disclosing the importance of the physical flows in satisfying customers properly. 


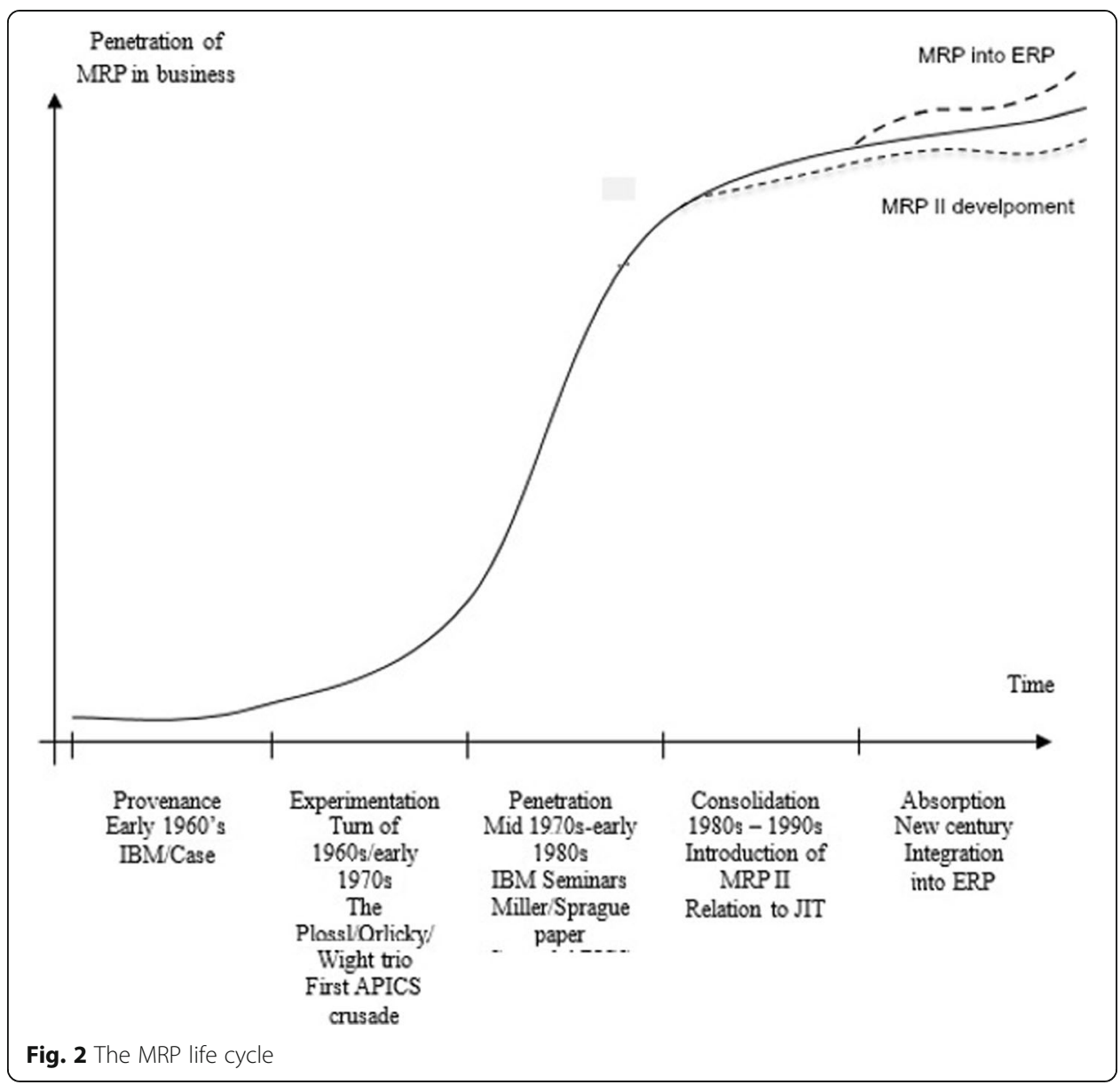

Increasing international activity in both sales and sourcing led to more complex coordination requirements.

In Fig. 3, Ballou [17] has a depiction of the development of SCM that shows the sequence of activity integration over time. Prior to 1960, coordination is performed by a collection of independent activities. By the late 1900s, those activities related to production are integrated in a pattern similar to the development of MRP. During the same time period those activities associated with getting the product to the customer are integrated into Physical Distribution (PD). The early development of PD was focused on outbound shipments and the integration of internal activities. A detailed description of the classical PD processes can be found in McKinnon [18] and for references on the connection between production, physical distribution, and purchasing see Spekman et al. [19].

In Fig. 3, one can see an example of big ideas in Operations Management evolving over time. As economies were found in the early phases (i.e., provenance and experimentation) of PD development, the next big idea, the logistics concept, entered the provenance phase. The logistics concept was to integrate the material flows with the customer flows. As experience with logistics increased, the next big idea was to integrate the other company functions and the customer into the supply chain management system. These big ideas evolved with considerable continuity and now are in the realm of the next big idea: integrating SCM into ERP. 


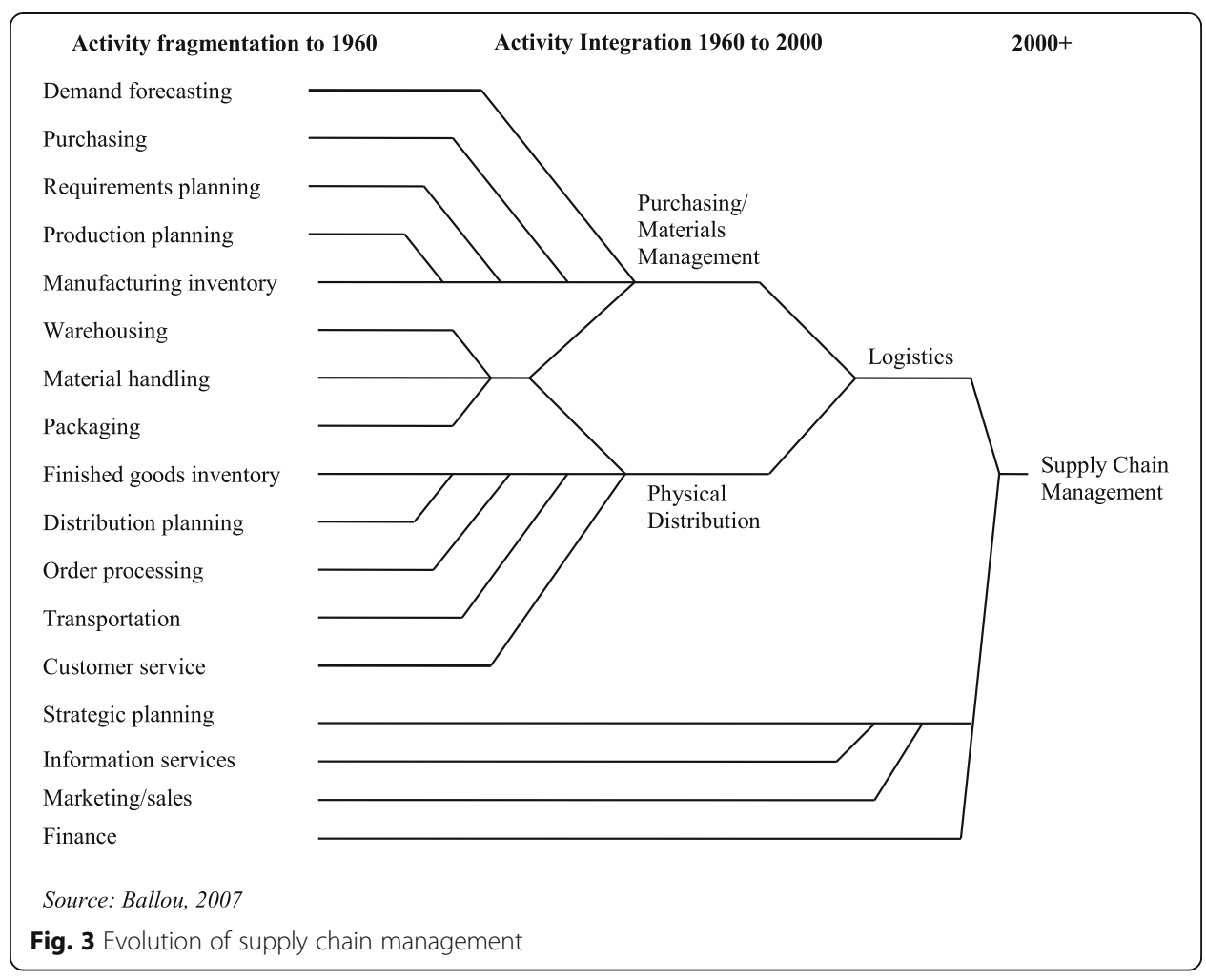

As these developments moved forward, the professional association was changing as well. Prior to 1960, the various independent activities, like warehousing and transportation, had their own individual professional associations. The National Council of Physical Distribution (NCPDM) arose to accommodate the Physical Distribution concept, taking in many members from the individual associations. The NCPDM evolved into the Council of Logistics Management (CLM) to accommodate the logistics concept. The organization is now known as the Council of Supply Chain Management Professionals (CSCMP) [20].

During the 1990s, the concept of SCM was already in the penetration and consolidation phases. It was already widely known and was a common topic in both practitioner and academic conferences. There still are discussions about its contents, questions about what it should be called, whether there is anybody that actually manages the chain, and whether it is a chain or network. Through more integrated operations and concentrating on core competences (hence building strong external relations), we have reached a point where no company can seek success without being part of an efficient supply chain (network). Concrete real world examples, however, tend to describe only dyadic relationships and no longer chains of multi-level, multi-company activities.

As for researching SCM, one cannot see any major impact of academics on practical development since most academic research also tends to be restricted to the dyad. After decades of research, there is still some academic debate about SCM: What is it, what is included, and where are its boundaries within and between companies. The literature is vast, with many attempts to synthesize knowledge-with partial success. Since the SCM concept itself has become broader and broader, new aspects of analysis became necessary [21]. There are also indications of new need in the practice-oriented 
literature (see Cousins et al. [22]). Johnson-Borger [23] argue that the development is organic and means just extending the original big idea (Physical Distribution) to a comprehensive, integrated (almost all-inclusive) function. Still the SCM life cycle development process can be illustrated as shown in Fig. 4.

\section{Conclusions}

Our conclusions are based on the comparison of the two life cycles (Figs. 2 and 4), which show the same pattern but the contents and consequences are rather different. Both their big ideas were born in practice. Both were developed during their experimentation and penetration phases. Both are results of developments in computer capability and well-identified business needs. Both had the support of academics and consultants as well as professional associations. Moreover, both have been absorbed into the fabric of everyday business activity. As such, their development over time basically followed the same life cycle through their widespread distribution.

However, there are important differences. MRP, for instance today, basically exists deep inside sophisticated computerized systems as a tool for tactical operations. The information generated by MRP is used to determine when and how many parts are to be produced on a particular machine. On the other hand, SCM is considerably more strategic in its scope and can involve suppliers and customers in coordinating the flow of material. Interestingly, despite the magnitude of change in practice and the breadth of implementation of both innovations, many of the individual physical activities remain the same as before. For example, parts are still produced on machines and trucks are loaded or unloaded today just like 50 years ago. Nevertheless, these big ideas have transformed the landscape of business practices for the better by adding value for the customer.

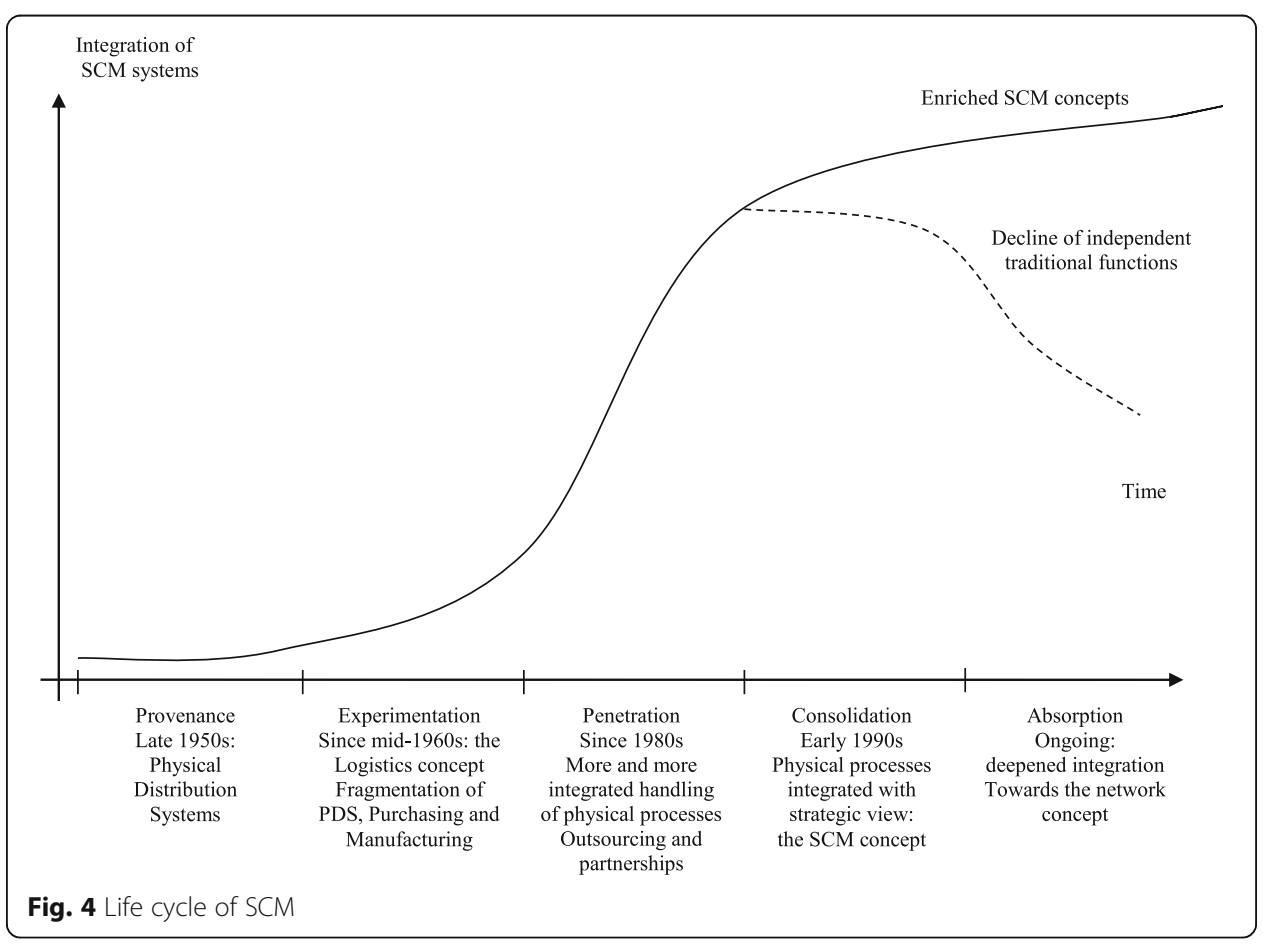


The prospects for further innovations in operations management is indicated by two features we discovered during the analysis of the life cycles. The first is that, during the development of both MRP and SCM, there were several "offspring" (like MRP II and ERP from MRP and logistics and outsourcing from SCM), which are based on new big ideas. These and others open up the possibility for the start of new life cycles. The second important observation is the increasing integration of using MRP and SCM. This is reflected both in the practitioners' approach (illustrated by the merger of two of the most powerful professional associations in the management of operations, APICS and SCC) and in the supporting literature [24]. These developments may point to the future of integration within and among firms in a number of industries. This integration is elevated to an even higher level with the appearance of cyber-physical systems. The analysis of these processes is still in the initial stage (see for example Klötzer and Pflaum [25] and Oborski [26]). The developments until now seem to support the message of this paper.

\section{Abbreviations}

APICS: American Production and Inventory Control Society; CLM: Council of Logistics Management; CSCMP: Council of Supply Chain Management Professionals; ERP: Enterprise Resource Planning; JIT: Just in time; MRP: Material requirements planning; NCPDM: National Council of Physical Distribution Management; OM: Operations management; PD: Physical Distribution; SCM: Supply chain management

\section{Acknowledgements}

D. Clay Whybark provided great help by editing and improving the professional and grammatical presentation of the material.

\section{Funding}

The paper was sponsored (sponsor code is: TEMP-KSQM).

Availability of data and materials

Data sharing is not applicable to this article as no datasets were generated or analyzed during the current study.

\section{Addendum from Attila Chikan}

As best I know this is the last article that Linda Sprague was working on when she died. As co-author I felt that this should be published in honour of the many contributions that she has made to the profession. I asked Clay Whybark to be the English editor of the submission and am most grateful for his invaluable help in improving the paper. We both hope that we have been faithful to her ideas. Linda has made innumerable contributions to our profession and we are proud to include this effort in her legacy.

\section{Authors' contributions}

AC has set the general framework of the development process and worked out the supply chain management example. LS has put the development process into the Life Cycle framework and elaborated the MRP agenda. Conclusions are the result of joint work. Attila Chikán read and approved the final manuscript.

\section{Authors' information}

Attila Chikán is Professor Emeritus of Corvinus University of Budapest, where he is Director of Competitiveness Research Centre. He is Past President of International Federation of Purchasing and Supply Management and of Federation of European Production and Industrial Management Societies. A former Minister of Economic Affairs of the Hungarian Government, he is on the boards of several business organizations.

Linda G. Sprague (+ 2013) was a HBS graduate. Main stations of her academic career included the University of New Hampshire (for three decades, creating parterships with European universities including IMD in Switzerland, Cranfield in England, and IESE in Barcelona) and the China Europe International Business School in Shanghai (ten years). She was among the key actors of APICS's famous "MRP Crusade". She served as President of the Decision Sciences Institute and the International Society for Inventory Research.

\section{Competing interests}

The authors declare that they have no competing interests.

\section{Publisher's Note}

Springer Nature remains neutral with regard to jurisdictional claims in published maps and institutional affiliations.

\section{Author details}

${ }^{1}$ Institute of Business Economics, Corvinus University of Budapest, Budapest, Hungary. ${ }^{2}$ China Europe Business School, Sanghai, China. 
Received: 30 January 2019 Accepted: 29 March 2019

\section{Published online: 10 May 2019}

\section{References}

1. Letscher MG (1994) How to tell facts from trends. Am Demogr 16(12):38-45

2. Spell C (1999) Where do management fashions come from and how long do they stay. J Manag Hist 5(6):334-358 https:/www.emeraldinsight.com/doi/full/10.1108/13552529910288127

3. Williams R (2004) Management fashions and fads. Manag Decis 42(6):769-780 https://www.emeraldinsight.com/doi/full/ $10.1108 / 00251740410542339 \% 20$

4. Voss C (2008) The evolution of best practices in operations (draft memo)

5. Sprague LG (2007) Evolution of the field of operations management. J Oper Manag 25:219-238 https://www. sciencedirect.com/science/article/pii/S0272696307000022

6. Mabert VA (2007) The early road to material requirements planning. J Oper Manag 25:346-356 https://www. sciencedirect.com/science/article/pii/S0272696306000301

7. Vollmann TE (1973) Operations management; a system model-building approach. Addison-Wesley Reading, Mass

8. New CC (1973) Requirements Planning. Gower Press, London

9. Miller, J.G, Spraque, L.G. (1975): Behind the growth in material requirements planning. Harvard Business Review, Sept-Oct https://hbr.org/1975/09/behind-the-growth-in-materials-requirements-planning. Accessed 27 Apr 2019

10. Vazsonyi A (1955) The use of mathematics in production and inventory control. Manag Sci (1):70-85 https://www.jstor. org/stable/pdf/2627160.pdf

11. Grubbström, R.G. (2009): Extensions of MRP theory with application to distribution and remanufacturing. Opening address, proceedings, Second International Workshop an Succesfful Strategies in Supply Chain Management, January, 8-9, 2009, Hong Kong, pp. 3-19 https://www.sciencedirect.com/science/article/pii/S1474667016337624. Accessed 27 Apr 2019

12. Bogataj M, Grubbström RW (2012) On the representation of timing for different structures within MRP theory. Int J Prod Econ 140:749-755 https://pdfs.semanticscholar.org/66f0/0eed28d8ef95a7d887bfc85b02033834dd2b.pdf

13. Bogataj M, Grubbström RW (2013) Transportation delays in reverse logistics. Int J Prod Econ (143):395-402 https://pdfs. semanticscholar.org/e5f0/2b8bf7bbb416a8423cb78597acc07d439e4f.pdf

14. Jacobs FR, Weston FC (2006) Enterprise Resource Planning (ERP) - a brief history. J Oper Manag 25(2):357-363 https:// www.sciencedirect.com/science/article/pii/S0272696306001355

15. Samson D, Singh P (2008) Operations management. An integrated approach. Cambridge University, Port Melbourne

16. Lummus RR, Vokurka RJ (1999) Defining supply chain management: a historical perspective and practical guidelines. Ind Manag Data Syst 19(1):11-17

17. Ballou PH (2007) The evolution and future of logistics and supply chain management. Eur Bus Rev 19(4):332-348 http:// www.scielo.br/scielo.php?script=sci_arttext\&pid=\$0103-65132006000300002

18. McKinnon AC (1989) Physical distribution systems. Routledge, London

19. Spekman, R., Kamauff, J.W. - Myhr, N.: (1998): An empirical investigation into supply chain management: a perspective on partnerships. J Supply Chain Manag, Vol. 3, No. 2., pp. 53-67 http://citeseerx.ist.psu.edu/viewdoc/download?doi=10.1. 1.476.5614\&rep=rep1\&type=pdf

20. APICS Finalizes merger with supply chain council, Chicago, August 5, 2014 http://www.apics.org/about/overview/ newsroom

21. Harland CM et al (2006) Supply management: is it a discipline? Int J Oper Prod Manag 26(7):730-753 https://www. emeraldinsight.com/doi/full/10.1108/01443570610672211

22. Cousins, P., Lamming, R., Lawson, B., Squire, B. (2007): Strategic supply management: principles, theories and practice, FT Prentice Hall, London, etc. https://researchportal.bath.ac.uk/en/publications/strategic-supply-management-principlestheories-and-practice

23. Johnson JC, Borger DL (1993) Physical distribution: has it reached maturity? Int J Phys Distrib Logist Manag 23(5):23-29

24. Jacobs FR, Berry W, Whybark DC, Vollmann T (2011) Manufacturing planning and control for supply chain management. https:/www.accessengineeringlibrary.com/browse/manufacturing-planning-and-control-for-supply-chain-managementthe-cpim-reference-second-edition

25. Klötzer, C., Pflaum, A. (2015): Cyber-physical systems (CPS) in supply chain management - a definitional approach, NOFOMA 2015 - towards sustainable logistics and supply chain management, Volume: 27 https:/www.researchgate. net/publication/301297231_Cyber-Physical_Systems_CPS_in_Supply_Chain_Management_-_A_definitional_approach. Accessed Sept 2018

26. Oborski P (2016) Integrated monitoring system of production processes. Manag Production Eng Review 7:86-96 https:// www.degruyter.com/downloadpdf/j/mper.2016.7.issue-4/mper-2016-0039/mper-2016-0039.pdf 